\title{
LINHAS DO ACOLHIMENTO NA SAÚDE: ENTRE MODOS DE TRABALHAR E ACOLHER
}

\author{
Lines Of Care In Health: Between Ways Of Working And Welcoming \\ Les Lignes d'Accueil Dans La Santé: Entre Les Modes De Travail Et D'accueil \\ Líneas De Acogida En La Salud: Entre Modos De Trabajar Y Acoger
}

\begin{abstract}
Gislei Domingas Ramanzini Lazzarotto ${ }^{1}$
Graduação em Psicologia e mestrado em Psicologia pela Pontifícia Universidade Católica do Rio Grande do Sul. Doutorado em Educação pela Universidade Federal do Rio Grande do Sul (2009). Professora do Departamento de Psicologia Social e Institucional do Instituto de Psicologia da UFRGS. Coordenadora do Grupo de extensão Estação Psi com ações em análise institucional e formação em psicologia no contexto de políticas públicas juvenis, educação e saúde coletiva; desenvolvendo atividades com as Faculdades de Educação e Direito no Núcleo de Extensão e Pesquisa do Programa Interdepartamental de Práticas com Adolescentes em Conflito com a Lei (PIPA). Experiência com ênfase em Psicologia Social e Institucional, atuando principalmente nos seguintes temas: subjetividade, análise institucional, educação, infância e juventude, dispositivos de expressão e escrita.

Pesquis adora vinculada ao Laboratório de Estudos em Linguagem, Interação e Cognição - LELIC-UFRGS Thiele da Costa Muller Castro²
Psicóloga, Mestra em Psicologia Social e Institucional pela Universidade Federal do Rio Grande do Sul (2010),
Residência em Saúde Coletiva com ênfase em Atenção Básica. Pesquisadora convidada do Laboratório de
Psicodinâmica e Clínica do Trabalho - LPCT/UnB, do qualé membro desde 2011. Experiência na área de
Psicologia, com ênfase em Análise Clínica do Trabalho, atuando principalmente nos seguintes temas: trabalho,
psicologia social, psicodinâmica do trabalho, reconhecimento e subjetividade. Sócia Proprietária da empresa
GEPSAT - Grupo de Estudos e Práticas em Clínica, Saúde e Trabalho, onde presta consultoria e assessoria em as suntos de saúde mental e trabalho.
\end{abstract}

\section{RESUMO}

Este artigo trata de pesquisa realizada como trabalho de conclusão da Residência Integrada em Saúde da Escola de Saúde Pública/RS (ESP/RS), que teve como tema o dispositivo do acolhimento da Política Nacional de Humanização (PNH) na Atenção Básica em Saúde. O objetivo foi analisar as práticas de acolhimento e os modos de subjetivar e trabalhar da equipe de uma Unidade Básica de Saúde (UBS), de Porto Alegre. A metodolog ia utilizada foi a pesquisa intervenção através de uma construção coletiva do processo de pesquisa. A análise do dispositivo acolhimento possibilitou estabelecer relações entre a organização e a gestão do trabalho na saúde, contribuindo na explicitação da necessidade de um processo de mudança a partir de uma demanda produzida nas falas dos trabalhadores. Percebeu-se a potência dos espaços coletivos e a implicação destes sujeitostrabalhadores na construção dos modos de trabalhar e acolher desta UBS.

Palavras-chave: Acolhimento; Política Nacional de Humanização; Saúde do Trabalhador; Trabalho em Saúde; Atenção Básica; Sistema Único de Saúde (SUS)

\footnotetext{
${ }^{1}$ E-mail: gislei.ufrgs@gmail.com

2 E-mail: thielemuller@msn.com
} 


\begin{abstract}
This article comes from a research at the end of the Integrated Health Residency of Escola de Saú de Pública/RS. The research has dealt with the welcoming disposal of the National Policy of Humanization (PNH) in Primary Health Care. The objective was to examine the practices of welcoming, ways of subjetify and the team work of a Basic Health Care Unit (BHU) on Porto Alegre. The methodology used was a research-action through a collective construction of the research process. The analysis of the welcoming disposal allowed to realize the relations between the organization and the management of work on health care, contributing to the explanation of the need for a process of change from a demand for speech produced by the workers. We realized the power of collective spaces and the implication of these subjects-workers in the construction of ways of working and accommodating of UBS.
\end{abstract}

Keywords: Welcoming; National Humanization Policy; Worker's health; Health Work; Basic Attention; Unified Health System (SUS)

\title{
RÉSUMÉ
}

Cet article traite de la recherche menée en conclusion de um étage dans la résidence intégré santé de l'École de Santé Publique, dont le thème était le dispositif de l'accueil pour la politique nationale de Humanisation (PNH) en soins de santé primaires. L'objectif était d'analyser les pratiques d'accueil et les moyens de subjectivement et le travail de l'équipe d'une unité de santé de base (BHU), à Porto Alegre. La méthodologie utilisée a été la recherche-intervention, une construction collective du processus de recherche. L'analyse du dispositif d'accueil a permis d'établir des relations entre l'organisation et la gestion du travail en matière de santé, ce qui contribue à l'explication de la nécessité d'un processus de changement d'une demande produite dans les discours des travailleurs. On a réalisé le pouvoir des espaces collectifs et l'implication de ces sujets-travailleurs dans la construction de méthodes de travail et d'accueillir cette UBS.

Mots-clés: Accueil; Politique Nationale Humanisation; Santé au travail; Travail en santé; primaire; Système de Santé Unifié (SUS)

\section{RESUMEN}

Este artículo trata de investigación realizada como trabajo de conclusión de la Residencia Integrada en Salud de la Escuela de Salud Pública / RS (ESP / RS), que tuvo como tema el dispositivo de la acogida de la Política Nacional de Humanización (PNH) en la Atención Básica en Salud. El objetivo fue analizar las prácticas de acogida y los modos de subjetivar y trabajar del equipo de una Unidad Básica de Salud (UBS), de Porto Alegre. La metodología utilizada fue la investigación-acción a través de una construcción colectiva del proceso de investigación. El análisis del dispositivo de acogida permitió establecer relaciones entre la organización y la gestión del trabajo en la salud, contribuyendo en la explicitación de la necesidad de un proceso de cambio a partir de una demanda producida en las conversaciones de los trabajadores. Se percibió la potencia de los espacios colectivos y la implicación de estos sujetos trabajadores en la construcción de los modos de trabajar y acoger de esta UBS.

Palabras clave: Acogida; Política Nacional de Humanización; Salud del Trabajador; Trabajo en Salud; Atención Básica; Sistema Único de Salud (SUS)

\section{INTRODUÇÃO}

Neste artigo apresenta-se a pesquisa realizada como trabalho de conclusão da Residência Integrada em Saúde da Escola de Saúde Pública/RS (ESP/RS), que teve como tema o dispositivo do acolhimento da Política Nacional de Humanização (PNH) na Atenção Básica em Saúde, e como objeto de pesquisa, a relação do acolhimento com os modos de subjetivar e trabalhar da equipe de uma Unidade Básica de Saúde (UBS). O objetivo foi analisar as práticas de acolhimento e como elas repercutem nos modos de trabalhar e subjetivar da equipe.

A proposta deste trabalho surgiu com a inquietação de como a equipe lida com o acolhimento e o que ela entende por acolhimento. As questões que nortearam a pesquisa foram: $\mathrm{O}$ que é o acolhimento de acordo com a Política Nacional de 
Humanização? Que relações podem ser estabelecidas entre a organização do trabalho, os modos de subjetivar e os modos de praticar o acolhimento da equipe de uma Unidade de Saúde? Quais estratégias a equipe constrói para assegurar o acolhimento?

O campo/plano da pesquisa foi uma UBS, na cidade de Porto Alegre, que procura oferecer ao usuário, além dos atendimentos em saúde, práticas educativas que o considere integralmente, resgatando e valorizando sua autonomia. Dentre os serviços oferecidos pela UBS estão os momentos de conversa com os usuários na sala de espera, acolhimento, consultas de pronto-atendimento, consultas agendadas (Medicina, Odontologia, Enfermagem, Serviço Social, Nutrição, Psicologia, Fisioterapia), visitas domiciliares e grupos de educação em saúde. A equipe contava, a época da pesquisa, com 12 residentes e 9 profissionais da equipe fixa. De acordo com informações da gerência distrital, a população atendida pela unidade era aproximadamente onze mil pessoas, todavia, a equipe acreditava ter mais usuários.

A metodologia utilizada foi a pesquisa intervenção, a partir de uma investigação participativa, levando em conta a construção coletiva do processo de pesquisa. Desta forma, a pesquisa foi realizada com trabalhadores da saúde, e não sobre estes, pois, segundo Aguiar e Rocha (2007), tanto pesquisadores quanto pesquisados são co-autores do processo de reconhecimento das atuais práticas e da construção de novos caminhos.

A sustentação teórica sobre $\mathrm{o}$ acolhimento foi feita a partir de documentos oficiais da Política Nacional de Humanização, portarias, diretrizes operacionais e de trabalhos feitos por pesquisadores que trabalham com o tema. Para a discussão sobre saúde do trabalhador foram utilizadas referências como Dejours (2005), Rollo (2009), Lancman e Pereira (2008).
A seguir é apresentado o desenvolvimento do estudo, que inicia com a concepção de acolhimento, seguindo com o delineamento metodológico, qual seja, a pesquisa-intervenção. $\mathrm{O}$ processo de pesquisa é apresentado relatando a forma como o acolhimento acontece na unidade. As análises seguem, levantando questões que tensionam a relação entre a saúde do trabalhador e o acolhimento. Apresenta-se a prática da residência como potência de produção coletiva que faz ressonâncias nas ações de trabalho, disparando a discussão sobre a necessidade da articulação entre gestão, práticas de cuidado e saúde do trabalhador para uma maior efetividade das ações em saúde pública.

\section{A proposição de uma política de acolhimento}

O acolhimento é entendido, pela PNH (BRASIL, 2004), como uma ação tecno-assistencial que pressupõe a mudança da relação profissional/usuário e sua rede social através de parâmetros técnicos, éticos, humanitários e de solidariedade, reconhecendo o usuário como sujeito e participante ativo no processo de produção da saúde. De acordo com a PNH (BRASIL, 2009) é através do acolhimento que se pode analisar e revisar a prática cotidiana da atenção e gestão implementadas nas unidades do SUS. Assim, ele passa a ser um instrumento não apenas para acesso ao serviço de saúde como também para avaliar os modelos de atenção.

O acolhimento, por ser uma atividade realizada por toda a equipe e no cotidiano da UBS, deve ser entendido tanto como diretriz ética/estética/política constitutiva dos modos de se produzir saúde, quanto como dispositivo, ferramenta tecnológica de intervenção na qualificação de escuta, construção de vínculo, garantia do acesso com responsabilização e resolutividade nos serviços. Diversos autores abordam o tema, tais como, Carvalho e Campos (2000), 
Campos (1997), Ramos (2001), Bueno e Merhy (1997), Pitta (1996), Pasche (2006), sempre trazendo a relevância de se problematizar o acolhimento $\mathrm{e}$ as formas de escuta envolvidas nas práticas de atendimento aos usuários da saúde, levando em consideração $\mathrm{o}$ vínculo construído entre usuários e trabalhadores e a relação humanizada na assistência.

Acolhimento, orientação ética, pois o toma como base do contrato entre os sujeitos que cuidam e os que são cuidados, cuja ação é produzir um campo comum que vamos chamar de produção do cuidado compartilhado, corresponsabilização. Acolher é, pois, o que inaugura e sustenta processos de cuidar. Acolher, todavia, não significa apenas interagir a partir do aceitar aquilo que o outro traz, mas, a partir disto, produzir desvios, produzir movimentos que permitam reposicionamentos, produção de novas atitudes, de novas éticas. (BRASIL, 2010, p. 66)

O conceito de acolhimento emerge do acúmulo prático dos serviços de saúde, muitas vezes utilizado como sinônimo de atitude de bondade, outras vezes tomado como local físico que transmite sensação de conforto. De acordo com a PNH (BRASIL, 2009) estas noções não podem ser tomadas isoladamente, quando isso acontece vemos os serviços de saúde conviverem com filas enormes que iniciam na madrugada, sendo que as pessoas são atendidas pelo critério da ordem de chegada e não pelo critério dos que necessitam de assistência. Segundo Abbês (2006), a ordem de chegada, o atendimento exclusivo através de agendamento prévio e um dia mensal para marcação de consultas são critérios inaceitáveis de acesso aos serviços de saúde da atenção básica. Esta forma de organização do trabalho compromete a eficácia e causa sofrimento não só aos usuários como também aos trabalhadores.

$\mathrm{Na}$ atenção básica o acolhimento, como diretriz, precisa ser entendido de uma forma ampliada, não restrita a porta de entrada, a um lugar físico, mas sim algo que possa ser trabalhado em todas as formas de encontros, pois ele se justifica na produção de saúde e por um regime de afetabilidade. E, quanto ação técnicoassistencial, deve garantir acesso com responsabilização e resolutividade nos serviços, avaliar os riscos e a vulnerabilidade e estar atento ao sofrimento tanto físico quanto psíquico do usuário. Assim, o conceito de acolhimento torna-se prática no cotidiano dos serviços quando há uma escuta qualificada e a capacidade de pactuar a demanda do sujeito e a possibilidade de resposta do serviço (BRASIL, 2009). Através da escuta, faz-se uma análise/avaliação da necessidade do usuário, distanciando-se de uma triagem, já que todos os usuários vão ser atendidos, independentemente da necessidade posterior de acessar outros serviços da rede ou não.

Entre tantos conceitos de acolhimento, destaca-se na orientação deste estudo a abordagem elaborada por Campos (2005, p.163), no projeto Paidéia: "acolhimento é receber bem, ouvir a demanda, buscar formas de compreendê-la e solidarizar-se com ela: deve ser realizado por toda a equipe de saúde, em toda relação profissional de saúde - pessoa em cuidado".

\section{2. $O$ processo da pesquisa: construindo uma metodologia}

A escolha da proposta metodológica foi ao encontro do modo como emerge o problema de pesquisa e as condições de possibilidade para percorrer sua análise. Para isso, pensa-se numa metodologia de pesquisa que consiga perceber a potência do objeto pesquisado sem procurar enquadrá-lo em uma forma, mas entender os movimentos deste. A 
pesquisa-intervenção, segundo Aguiar e Rocha (2007), busca uma movimentação coletiva para produção de micropolíticas de transformação social, envolvendo articulação da ação histórica de indivíduos, grupos, coletividades e de normas sociais.

O pesquisador não se posiciona como um intérprete, mas como agente de invenção de novas possibilidades, de rupturas de sentido (AGUIAR \& ROCHA, 2007). Atua percorrendo a trama do acontecimento, com um olhar livre, fazendo escolhas, puxando algumas linhas que a compõem. Essas linhas podem ser compreendidas como linhas de um dispositivo, que segundo Kastrup e Barros (2009), caracteriza-se pela capacidade de irrupção naquilo que se encontra bloqueado para a criação. Ele tensiona, movimenta, desloca.

A escolha pela pesquisa sobre o acolhimento emerge da experiência de quem pesquisa e viveu esse acontecimento com colegas residentes, equipe e usuários da UBS em que se constitui o campo de prática. $\mathrm{O}$ processo de pesquisa não iniciou no momento de uma delimitação de tema para um trabalho de conclusão, mas sim no decorrer da trajetória da pesquisadora durante a residência. A problematização do tema do acolhimento gerou uma demanda também para preceptoria coletiva ${ }^{3}$ na UBS, momento onde se falava sobre a prática de acolher e os sentimentos de quem ocupa este lugar, evidenciando a relevância do tema no cenário da prática.

\subsection{Passos da pesquisa}

$\mathrm{O}$ projeto de pesquisa foi aprovado pela Comissão Local de Ensino e Pesquisa e pelo Comitê de Ética e Pesquisa da Secretaria Municipal da Saúde do Município de Porto Alegre, registro do CEP 440, e Processo Número 001.061767.09.3. O campo de pesquisa envolveu as práticas de acolhimento de

\footnotetext{
3 A preceptoria é um espaço de ensino, supervisão e discussão das práticas cotidianas do serviço e a inserção dos residentes nos locais de formação.
}

uma UBS no período de outubro de 2009 a outubro de 2010. Através destes momentos, foi possível acompanhar a atividade de acolhimento na unidade; fazer uma descrição quantitativa dos acolhimentos realizados no ano de 2009; identificar a organização do trabalho no acolhimento; discutir com referencial teórico as práticas de acolhimento e as relações com a saúde dos trabalhadores, considerando as políticas do acolhimento.

Para conhecer, registrar e refletir sobre os acontecimentos que envolviam essas práticas e compor o corpo de dados da pesquisa foram utilizados:

a) Diário de Campo: utilizado pela pesquisadora residente, no qual eram registradas as observações e vivências no dia a dia de trabalho no acolhimento, as discussões de equipe a respeito desta prática, estudos do grupo de residentes e discussão do núcleo de psicologia da residência.

b) Cadernetas: foram entregues 26 cadernetas para a equipe fixa, profissionais da equipe de matriciamento, residentes $\mathrm{e}$ estagiários, com a seguinte questão orientadora: "conte um dia de acolhimento". A solicitação desta escrita tinha por objetivo oferecer um momento individual aos trabalhadores para narrar como viviam o trabalho do acolhimento e estabelecer relações destas narrativas com as vivências acompanhadas e registradas no diário de campo. Tomou-se a anuência dos participantes através do Termo de Consentimento Livre e Esclarecido. Para a entrega da caderneta à pesquisadora foi combinado prazo de uma semana. Prazo este que não se cumpriu. Apenas seis cadernetas foram entregues, no decorrer de três meses. 
c) Levantamento de documentos sobre a PNH e as diretrizes de Acolhimento: cartilhas e Documento Base.

Dispondo do diário de campo, das narrativas das cadernetas devolvidas e dos estudos de documentos e referenciais bibliográficos colocava-se como questão construir um modo de análise e compreensão do que havia sido produzido com a pesquisa. A possibilidade de narrar a experiência evidenciava a presença de uma análise orientada por uma política da narratividade, que segundo Passos e Barros (2009, p.151) envolve "uma posição que tomamos quando, em relação ao mundo e a si mesmo, definimos uma forma de expressão do que se passa, do que acontece".

Assim, a análise desenvolve as relações construídas entre o dispositivo de acolhimento da PNH e as respectivas linhas de sua implementação no contexto da UBS pesquisada. Neste percurso emergem linhas de análise que apontam a experiência do acolhimento como trama de um nó no viver dos trabalhadores de saúde na relação com usuários. É nesta trama que vão sendo analisadas as situações que geram sofrimento nos trabalhadores, considerando as narrativas do diário e das cadernetas e a compreensão teórica da Psicodinâmica do Trabalho (DEJOURS e MOLINER, 2004).

\section{Modos de trabalhar, acolher e subjetivar}

Os modos de organizar 0 acolhimento vão sendo produzidos a partir da orientação da $\mathrm{PNH}$, no entrelaçamento com as práticas e o cenário no qual a equipe constitui seu fazer numa determinada UBS. Para evidenciar como foi sendo construída a questão de pesquisa na temática acolhimento se faz necessário relatar o funcionamento desta prática. Assim, vão sendo delineadas as linhas do nó que se apresenta como problemática deste estudo: as relações entre a organização do acolhimento e o sofrimento dos trabalhadores de saúde.

No início do processo de pesquisa, o acolhimento se organizava com uma escala semanal onde cada residente era responsável por um turno de acolhimento; no turno que os residentes não estavam na unidade a responsabilidade ficava com a equipe fixa. Acolhedor era aquele que estava na mesa, encarregado de distribuir as fichas pela ordem de chegada, avisar aos que não conseguiram fichas, que deveriam procurar outro serviço, e organizar o fluxo para que passassem na mesa para identificação os que iriam consultar.

Para situar o volume de atendimentos realizados nesta UBS, foi feito um levantamento de dados nas planilhas de acolhimento, retrospectivo de janeiro a dezembro de 2009. Foram acolhidas, mensalmente, uma média de novecentas pessoas. Esses números referem-se ao acolhimento, como pensado nesta UBS, através da mesa onde fica o acolhedor do dia, fazendo, como chama a equipe, o "aplanilhamento". Esses dados não compreendem o total de usuários que chegaram até a UBS, os que foram apenas retirar exames e pegar referências para outros serviços, que foram marcar agenda médica ou multiprofissional e os que procuravam atendimento, mas não conseguiram, tarefas também realizadas pelo acolhedor.

A equipe contava com médicos tanto no turno da manhã como no turno da tarde, assim, havia atendimento médico e multiprofissional o dia todo. $\mathrm{O}$ serviço abria as portas pela manhã, às oito horas, quando os usuários já formavam uma fila enorme para atendimento. Ao abrir, todos os usuários sentavam, em ordem de como estavam na fila, ordem de chegada, e as fichas para atendimento eram distribuídas. Havia dez fichas para pronto atendimento ${ }^{4}$

$4 \mathrm{O}$ pronto atendimento é entendido como uma consulta médica destinada para pessoas que não passaram bem durante a noite e que, 
pela manhã, e cinco fichas eram distribuídas para atendimento à tarde. Além do pronto atendimento, existiam as consultas médicas agendadas, consultas que seriam de retorno para acompanhamento dos crônicos ${ }^{5}$, análise de exames, Pré-Natal, Prá-Nenê e outros grupos, como por exemplo, o de Saúde Mental e de Qualidade de Vida.

Com a distribuição das fichas, os usuários atendidos naquele turno permaneciam na unidade e "passavam no acolhimento", enquanto os que não conseguiram a consulta voltavam para casa ou procuravam outros serviços. Ao passarem no chamado acolhimento, os usuários identificam-se através do nome, endereço, idade e o motivo da consulta. E, logo passariam para triagem para aguardar a consulta. Neste espaço chamado de "acolhimento", que fica em um corredor, entre a sala de espera e o corredor que dá acesso aos consultórios e triagem, não há nenhuma privacidade, e ali o profissional acaba sabendo apenas os dados do usuário e separando o prontuário para a consulta.

Nesta forma de organizar o trabalho emerge uma das linhas que nos faz indagar as práticas de acolhimento nesta UBS: a não escuta aos usuários à medida que ao disponibilizar atendimento apenas para os quinze primeiros da fila não há uma adequada avaliação da solicitação e do sofrimento do usuário. Assim, o usuário é menos percebido integralmente, e mais designado pelo registro de dados mínimos para preenchimento de uma planilha sobre aqueles que irão consultar conforme a ordem de chegada. $\mathrm{O}$ acolhimento nesta UBS não era um processo que primava por atender todos que buscavam o serviço de saúde, através da escuta e da tentativa de uma forma de atendimento ao pedido do

consequentemente, não teriam como agendar uma consulta previamente

5 Crônicos é a forma como se nomeia os pacientes portadores de alguma doença que não é resolvida em um tempo curto, assim, precisa de acompanhamento freqüente. A doença crônica não é classificada como urgência médica, mas podem ser extremamente sérias. usuário, tal como afirma a PNH. Acolher não se restringe a consulta médica ou multiprofissional imediata, mas $\operatorname{sim}$ a coordenação do cuidado, a marcação de uma agenda ou a articulação da rede através do acionamento de outros serviços, e por isso é preciso escutar o pedido e analisar a demanda.

Ao prosseguirmos acompanhando o "processo de acolher" chegamos à triagem. Nesta UBS a triagem era realizada pela equipe de técnicos de enfermagem, havia a verificação da pressão arterial, temperatura corporal, avaliação de peso e altura. Muitas vezes, era nesse momento que a equipe saberia o real motivo do usuário procurar a unidade de saúde. $\mathrm{Na}$ sala da triagem havia um fluxo muito grande de passagem de pessoas, e a equipe não conseguia desempenhar todas as tarefas de tamanha solicitação, provocando um congestionamento no fluxo do serviço, pois lá também eram dispensados medicamentos e efetuada pesagens do Programa Bolsa Familia. Então, o tempo de espera para triagem atrasava o início dos pronto-atendimentos e das consultas agendadas de todas as profissões. Temos aqui outra linha que vai sendo tramada neste modo de organizar o trabalho: a estrutura física. A unidade básica de saúde não dispunha de outras salas para aliviar este fluxo.

Neste tempo da pesquisa também foram sendo evidenciados aspectos sobre a contratação dos trabalhadores e o modo de realocá-los nos serviços de saúde. Os funcionários contratados pela FUGAST $^{6}$, por conta de uma ação do Ministério Público na Justiça, estariam em situação irregular, assim, ameaçados de serem demitidos. Em determinado momento essa ameaça se concretiza, a equipe ficou com um número reduzido de médicos, impossibilitando a abertura do serviço no turno da tarde, sendo que a equipe passou

\footnotetext{
6 FUGAST: Fundação de Gastroentereologia, entidade de caráter privado que mantém convênio com governo estadual e contrata funcionários para trabalhar no SUS em regime da CLT.
} 
de 31 pessoas para 21. Com esta situação, o atendimento a comunidade ficou mais precário. O número de consultas que já eram insuficientes para os moradores do território ficou ainda menor. Essa situação gerou descontentamento tanto nos usuários quanto nos trabalhadores da saúde, bem como comprometia as condições para as práticas de acolhimento.

O fluxograma da UBS, na figura a seguir, ilustra graficamente como era $\mathrm{o}$ processo de trabalho, ele surge como ferramenta analisadora (Barboza, 2005) se constituindo num instrumento de análise, que interroga os "para que", os "que" e os "como" dos processos de trabalho, e ao mesmo tempo revela a maneira de governá-lo. Utilizamos uma marcação sob o acolhimento, pois de acordo com a leitura da equipe este é um dos nós críticos deste processo, e uma marcação sob as consultas e serviços de referência, sendo estes pontuados como diretamente afetados pela forma como o acolhimento acontecia.

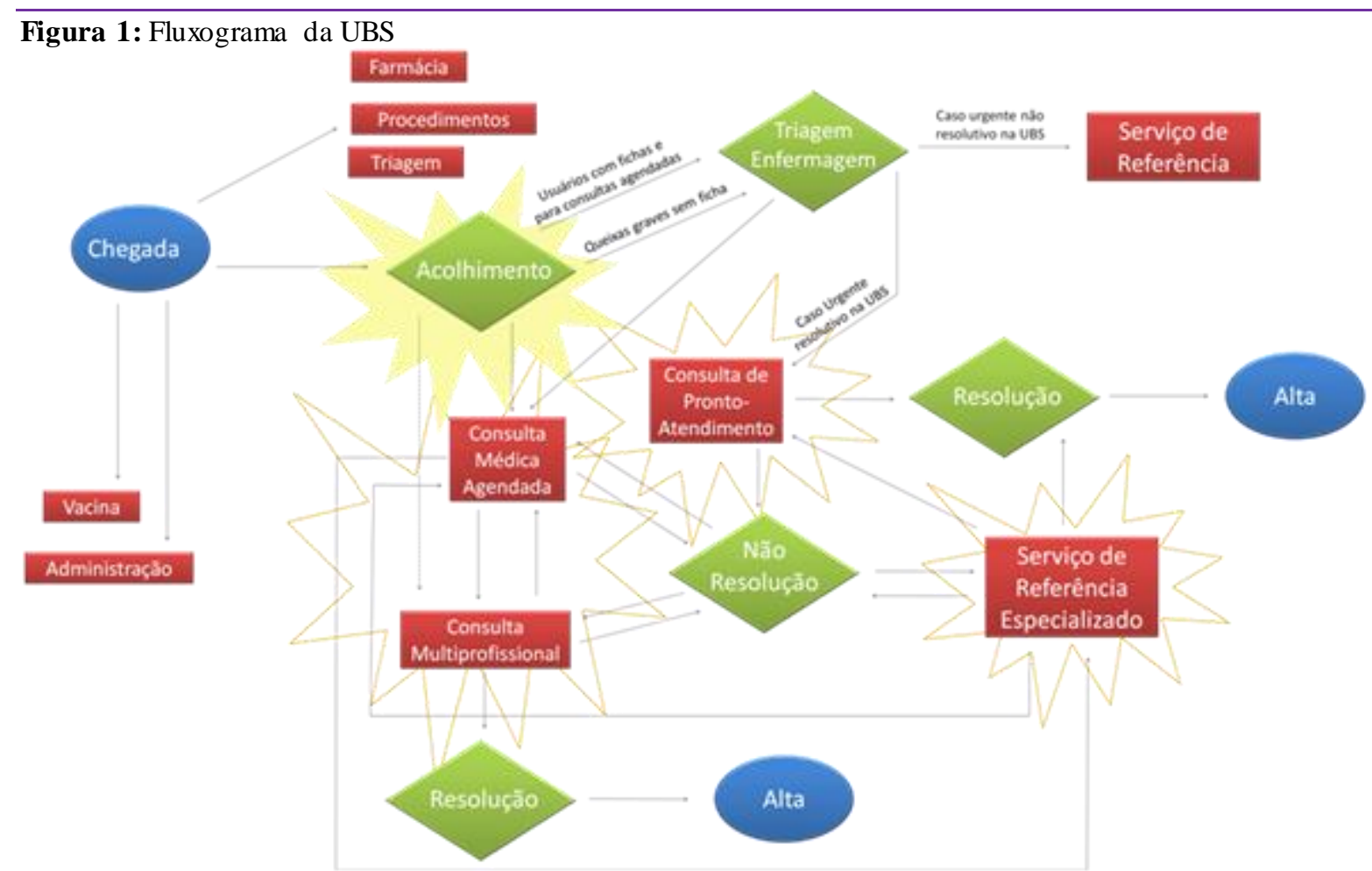

Fonte: fluxograma desenhado pelas autoras

Outra linha de problematização percebida envolve as consultas de prontoatendimento, que muitas vezes eram utilizadas pelos usuários não para seu real objetivo, mas sim para mostrar exames solicitados em consultas anteriores, já que não existiam agendas para retorno. Então, os casos que de fato eram agudos e emergenciais, acabavam chegando à unidade mais na metade da manhã, quando todas as fichas já tinham sido distribuídas. Esses casos não podiam ser negligenciados, quando a equipe conseguia acolher e perceber o risco do usuário, eram atendidos adicionalmente, superlotando $\mathrm{o}$ serviço.

Também constitui o "nó" da organização do acolhimento a demora na marcação de consultas no Serviço de Referência Especializada principalmente para consultas de traumato-ortopedia, neurologia, cardiologia, urologia e endocrinologia. Nesta UBS, um técnico de enfermagem realizava esta tarefa, mas enquanto isso, os serviços de enfermagem ficavam sobrecarregados. $\mathrm{O}$ modo de agendar as consultas médicas e multiprofissionais e o modo como os usuários respondiam a este funcionamento 
também evidenciaram linhas de análise deste trabalho. Incapacidade de atender a demanda, longo período de espera entre consultas de acompanhamento; o não comparecimento de usuários às consultas; e usuários de outros postos marcando consultas nesta UBS.

É neste cenário de prática do acolhimento que escutamos dos trabalhadores inquietações com esse modo de trabalhar gerando a vontade de pesquisar sobre essa questão. Ao aguçar a escuta para as questões referentes ao acolhimento, entre as inquietações dos trabalhadores duas falas marcam 0 percurso deste pesquisar:

\section{$\rightarrow \quad$ "A gente carrega um não nas costas". \\ $\rightarrow \quad$ "Ser acolhedor tem prazo de validade".}

Essas falas passam a ser pistas, pistas que estiveram presentes, de uma forma ou de outra, em todos os passos do trajeto da pesquisa no sentido da curiosidade para compreender e analisar os modos de praticar esse lugar de acolher marcado pela sensação de não acolher e pela urgência de sair desta função. As pistas, segundo Passos, Kastrup e Escóssia (2009, p.13), "são como referências que concorrem para a manutenção de uma atitude de abertura ao que vai se produzindo e de calibragem no caminhar no próprio percurso da pesquisa. "

Acolher essas falas como parte do processo que produz o acolhimento como um "nó", faz da pesquisa uma possibilidade de contribuir na análise e na criação de linhas que façam do nó um dispositivo de mudança. Para a estratégia da pesquisa intervenção vai compondo este estudo numa perspectiva de produção de conhecimento compartilhada com a experiência da residência.

\section{Linhas de Análise}

Partindo da concepção do dispositivo de acolhimento da PNH, é identificada na experiência desta UBS, a emergência de linhas que entrelaçam a prática do acolhimento constituindo um nó a ser analisado. As linhas deste nó apresentadas na parte 4 enunciam como os trabalhadores organizam e são organizados no processo de trabalho que dá forma ao modo de praticar o acolhimento. É nesta trama que se faz a análise das linhas que articulam a discussão da questão desta pesquisa: as relações estabelecidas entre a organização do trabalho, os modos de subjetivar e os modos de praticar o acolhimento nesta experiência e as estratégias que a equipe constrói para assegurar o acolhimento.

Para tal busca-se a compreensão teórica da Psicodinâmica do Trabalho para dialogar com as narrativas do diário e das cadernetas construindo a discussão deste material que constitui o corpo de dados da pesquisa. Destaca-se que esta produção de análises não se restringe ao momento da escrita deste artigo, pois é fruto de encontros construídos no processo de acolher e pesquisar com trabalhadores e usuários da saúde. Assim, a análise relatada não se apresenta como uma verdade, nem como única possibilidade, mas como versão de um processo que segue para além da pesquisa com aqueles que compartilharam as inquietações deste pesquisar.

Dejours e Moliner (2004, p.91), quando falam da escrita de um relatório de pesquisa e das análises feitas, lembram: " $\mathrm{O}$ pronunciado pode tomar a forma de texto. Mas o texto, por sua vez, ganha uma vida própria, que transcende o seu autor e produz resultados que escapam, às vezes, à intenção inicial. "Rocha e Aguiar (2003) afirmam que vem se evidenciando uma forma de investigação contrária ao mito da objetividade como única forma de produção de conhecimento. Dessa forma, a neutralidade e isenção do pesquisador não são mais vistos como única forma de 
verdade em pesquisa. Eis então a construção de um momento da vida.

Neste processo percebe-se a experiência de "ser acolhedor" de formas muito diferentes, pois cada trabalhador vai construindo seu próprio saber-fazer na medida em que o trabalho vai acontecendo na relação com a prescrição de suas atividades. Nesta relação entre o prescrito e o "jeito" próprio de fazer encontra-se a enunciação de modos singulares de trabalhar e pensar suas práticas.

Durante as discussões, a concepção que os trabalhadores tinham do acolhimento perpassavam diferentes formas de entendimento. Falava-se do espaço físico, da mesa onde fica $o$ acolhedor do dia, de uma nova lógica de recepção, de uma postura de conseguir fazer o outro sentir-se acolhido e também se falava em resolutividade. Com estas diferentes formas de entender 0 acolhimento, torna-se difícil poder falar de uma prática única, já que cada um a entende e a formata de uma maneira diferente.

Entretanto, por mais que as concepções do acolhimento divirjam, a escuta é algo que perpassa por todas as discussões, seja qual for a concepção de acolhimento que o profissional vai construindo na estratégia de seu fazer. Carneiro et al (2006), pontuam que a escuta pela escuta não traz resolutividade. A escuta deve ser qualificada, não basta que a equipe esteja disposta a ouvir o usuário, ela deve vir acompanhada de critérios técnicos e práticos para que não caia no vazio.

Segundo Pasche (2006), o acolhimento é um dos processos que gera mais dor e sofrimento aos trabalhadores da saúde. Para suportar o sofrimento que, segundo Dejours (2004), é inerente ao trabalho, os trabalhadores constroem estratégias defensivas coletivas e individuais. Uma das estratégias é ensurdecer e silenciar-se diante do outro que sofre, que se evidencia nesta narrativa: “[...] ficar apático no acolhimento é até uma forma de se proteger, de não se afetar. Não querer nem ouvir para não ter que dar alguma resposta. Que para o acolhedor pode ser visto como negativa, mas só a escuta, o encontro para o usuário pode ser visto como positivo"?

A evitação se mostra como uma estratégia na luta contra o sofrimento, no momento em que se pode evitar passar pelo acolhimento. Uma estagiária relata: "Percebi que evito o acolhimento, sempre passo bem rápido por aquela mesa. Dá a impressão de que a qualquer hora um vai te agarrar pelo braço e te pedir alguma coisa que você não pode, ou não sabe, ou não tem tempo para resolver" (Caderneta I). Com este enunciado percebe-se quanto o acolhimento produz sofrimento nesta equipe, e os trabalhadores começam a se organizar em uma lógica em que não se fica muito tempo como acolhedor, isso se explicita na seguinte fala: "Se pudéssemos medir diria que um profissional da saúde tem uma taxa de "saturação" do real acolhimento, em seguida passa a fazer como obrigação para então chegar a uma etapa de sofrimento" (Caderneta IV). Pasche (2006) parece concordar com essa fala, referindo que ninguém poderia ficar nessa tarefa por mais de seis meses.

Os profissionais referem $\mathrm{o}$ acolhimento como um "aplanilhamento", uma "recepção fajuta", "uma tortura", "um turno perdido", "assédio moral", "lugar enlouquecedor". Essas marcas de impossibilidade de o acolhimento acontecer como efetividade do trabalho, dizem das linhas de uma prática de acolhimento que se produz como nó expresso na pista: - "A gente carrega um não nas costas". A estratégia para não ficar neste lugar se faz desta experiência do não, efeito do modo de lidar deste trabalhador na trama do funcionamento da UBS e da gestão desta política pública. Como foi analisado, quanto a organização da prática do acolhimento, encontram-se linhas que enredam a rede a ser construída

7 Trecho retirado do diário de campo. Registro de conversa com uma residente. 
para que o acolhimento aconteça. Se emerge um nó, as linhas que conectam e criam elos estão embaraçadas, seja nas relações entre trabalhadores e entre disciplinas e áreas profissionais, seja na rede de serviços da comunidade e em áreas especializadas, seja ainda na relação da UBS com usuários para compor o acolher para além da solicitação, da queixa e da ausência das marcações.

Ao constatar a angústia nas falas dos trabalhadores sobre este lugar de acolher, percebe-se que o nó-acolhimento, deixa de ser processo em rede, para alguém dar conta da "mesa de acolhedor". Esta aparece mais como uma prática administrativa, de organizar o fluxo dos usuários que irão passar para as consultas. De acordo com a fala de uma residente, "apenas os (usuários) sortudos passam para o acolhimento" (Caderneta III). O que vem dizer do critério da ordem de chegada para os atendimentos.

As filas na madrugada e a incerteza de um atendimento colocam a população "contra" a equipe. Problemas semelhantes foram identificados em uma pesquisa realizada com usuários e trabalhadores no município de Quixadá, Ceará (CARNEIRO et al, 2006), onde percebeu-se o descaso, a desatenção, as filas longas, a demora para os atendimentos referidos pelos usuários, enquanto os trabalhadores queixavam-se da falta de educação dos usuários, a violência e o desrespeito.

Assim, vamos esclarecendo as marcas que compõem os vestígios deixados pela outra pista deste pesquisar: "Ser acolhedor tem prazo de validade". $\mathrm{O}$ acolhimento vai sendo marcado como um modo de subjetivar relacionado ao lugar ocupado na organização do trabalho, em determinadas tarefas e no tempo possível de "suportar" o "não nas costas", portanto com prazo de validade. Assim, vai sendo construído um modo de ser acolhedor associado a um modo de sofrer no trabalho.

As relações que transversalizam o trabalho na saúde são complexas, usuários com técnicos, técnicos com gestores, técnicos com técnicos, gestores com usuários, e estas relações são capazes de produzir inúmeros movimentos e jogos políticos. Os trabalhadores falam que estar no acolhimento é uma situação constrangedora, pois não existe estrutura para atender os usuários, não há médicos para acolher a demanda da população, o território (área adscrita) é muito grande para a capacidade de atendimento da equipe. Segundo Lancmann e Pereira (2008), o que altera os ritmos prescritos é a demanda superior ao que a equipe tem condições de atender, alterando a forma do atendimento e a ação do cuidado, não realizando esta como o desejável. As autoras ainda pontuam o desacordo que há entre os valores do trabalhador, aquilo que ele acredita ser um trabalho de qualidade, com a forma com que este realmente realiza seu trabalho.

Carneiro et al (2006) pontua que a fragmentação no processo de trabalho em saúde reflete diretamente nas relações interpessoais da equipe, gerando interações quase nulas e o despreparo para lidar com dimensões subjetivas no cotidiano de suas práticas, o cuidado em saúde. Segundo o autor (p. 14) há a "necessidade de harmonizar o processo de trabalho com o produto final almejado, qual seja a promoção de saúde e o bem-estar. "

De acordo com uma residente: "Processo de trabalho desorganizado aparece no acolhimento" (Caderneta II). O acolhimento é uma tecnologia de encontro, e realmente implica mudança no processo de trabalho, no modo de operar os processos de saúde. Implica qualificação e humanização da assistência, consequentemente mudança no modo de fazer e de concepção da gestão. Para Abbês (2006), falar de acolhimento não é simples, pois ele é uma diretriz que puxa outras, como a clínica ampliada e a cogestão, por isso precisa repensar todo o processo de trabalho, e na valorização do trabalhador. 
Pasche (2006) sustenta a ideia de que valorização do trabalhador é incluí-lo no processo de gestão. Isso vai ao encontro da fala de um residente: "fica a questão: como o profissional de saúde pode prestar um verdadeiro acolhimento e uma prática humanizada para os usuários do SUS se os próprios profissionais não se sentem acolhidos e nem respeitados pela gestão, precisando conviver com um clima de muitas incertezas e de precarização do trabalho" (Caderneta V). Este enunciado reflete como a clínica ainda é experienciada separada da gestão, no cotidiano desta unidade a co-gestão ainda não havia saído do papel, não passava de uma diretriz sem aplicabilidade.

\section{O movimento compartilhado de pesquisar}

Com a problematização do tema, muitas pessoas se mobilizaram a fim de parar o trabalho e discutir, em alguns momentos, o acolhimento. A primeira brecha formal ocorreu durante uma reunião sobre a preceptoria de campo, em que a pauta era eleger $\mathrm{o}$ assunto para a preceptoria em um novo formato, que agora seria feita com o grupo todo de residentes da unidade, em coletivo. Depois de muito debate, o tema eleito foi $o$ acolhimento, para isso foram sugeridas leituras a serem realizadas para o próximo encontro.

Pode-se tomar este movimento como uma das estratégias produzidas pela residência, como lugar de diferenciação que escuta as vozes que emergem nos acontecimentos de uma UBS. Escutar não diz respeito somente a solicitação do usuário, mas também do encaminhamento do colega e da solicitação institucional produzida na organização da UBS. Colocar em pauta este assunto que transborda nas práticas cotidianas, é afirmar sua importância, refletindo sobre como repercute em todas as práticas dos profissionais de saúde. Ao destacar alguns problemas do processo de trabalho, o real foco era chamar atenção para as possibilidades de intervenções em torno de tais situações. Assim, durante a discussão pode-se falar da falta de planejamento, que resulta em um desconhecimento das metas da unidade, e de um não conseguir efetivamente pensar em suas práticas cotidianas de produção de saúde. Para se ter uma postura ética e política como apontada pela $\mathrm{PNH}$ tem-se que pensar saúde de uma perspectiva mais ampla, não apenas levando em consideração a diretriz do acolhimento, mas a mudança de todo processo de trabalho.

E esta lógica de pensamento apareceu claramente durante as preceptorias coletivas. Onde as pessoas passaram a ter uma visão da complexidade de se trabalhar em uma unidade de saúde, tendo um aparato de diretrizes e dispositivos que foram pensados justamente para uma atitude que implique um compromisso coletivo de potência. Potência por supor os encontros entre os usuários e profissionais da saúde como gerador de um novo, de uma outra possibilidade de ser e estar naquele território.

Segundo Dejours e Moliner (2004, p. 80) “é possível que a intervenção dos pesquisadores em coletivo afete a estrutura de todo espaço de discussão comum em situação real do trabalho", assim como os trabalhadores e os pesquisadores também saem diferentes depois deste encontro.

Foram com estas possibilidades de intervenção que não só a UBS como os agentes desta tomaram como princípio propulsor os espaços coletivos de fala e a potência dos encontros de discussão e construção, produzindo outra forma de operar os conceitos de referência para nossas práticas. Iniciou-se um trabalho de conhecer para além da solicitação, a real demanda dos usuários, e para isso os residentes de primeiro ano foram para a sala de espera fazer um levantamento do que os usuários estavam buscando na UBS, que tipo de consulta, com qual profissional e por qual motivo. 
Depois de conhecer a demanda, pode-se colocar em ação um projeto piloto, que ocorreu durante dois dias com uma nova proposta de acolhimento. Não se entregou ficha para consultas, mas sim passaram na mesa do acolhimento todas as pessoas que procuraram a unidade nestes dois dias. A partir da escuta percebeu-se que muitos casos poderiam ser resolvidos com outros profissionais que não os médicos. E propôs-se, na reunião de planejamento, que ficaria como referência de acolhimento do dia duas pessoas da equipe, uma encarregada pela recepção, e outra pelo acolhimento. Pasche (2006) traz que acolher é uma atitude que comporta todos os trabalhadores da saúde, mas na organização do processo de trabalho muitas vezes temos que nos perguntar quem vai fazer este primeiro "enfrentamento" com a demanda que chega. Assim, a equipe começou a contar com uma recepção, um acolhedor, com local reservado para escuta com privacidade, e uma equipe de retaguarda para atendimento da demanda, além dos grupos que ainda aconteciam e as agendas de Pré-Natal, Prá-Nenê e Crônicos.

\section{Considerações finais}

Percorrer pela produção técnica sobre o acolhimento e a Política Nacional de Humanização possibilitou perceber que não existe uma receita para a implantação deste dispositivo já que não se pode entender que o acolhimento é algo implantável, mas sim está sempre em processo de "implantar ações". A aposta na construção do acolhimento é viável à medida que pararmos para pensar o processo de trabalho, e isso deve estar alicerçado na discussão sobre saúde e trabalho.

Esta pesquisa valeu-se da análise do dispositivo acolhimento para aquecer a discussão sobre esta prática e contribuir na explicitação da necessidade de um processo de mudança a partir de uma demanda produzida nas falas dos trabalhadores. Percebeu-se a potência dos espaços coletivos e da necessidade de uma co-gestão, o que envolve a implicação destes sujeitos-trabalhadores na construção do planejamento da UBS. Isso também exige que o profissional esteja aberto para receber o usuário, respeitar sua concepção de saúde e escutar sua demanda.

Em contrapartida, as mudanças desejadas nos processos de trabalho visando a humanização, promoção de saúde e resolutividade, geram novas exigências para os trabalhadores e gestores. Os novos modelos de gestão e atenção propondo maior participação dos trabalhadores nos processos explicitam a necessidade tanto de novos conhecimentos e habilidades, como de discussões sobre a formulação e execução de políticas no âmbito da gestão e do controle social.

Como já dito, quando se fala na diretriz do acolhimento, é impossível não falar de outras diretrizes, neste momento de conclusão de trabalho, a diretriz que é atraída para a discussão é a da valorização do trabalho e do trabalhador, que com certeza refletirá em todas as outras diretrizes e princípios da PNH e do SUS.

\section{Referências}

ABBÊS, Claudia. (2006) O Acolhimento como Diretriz Clínica: Redes de Conversações. In: BRASIL. Ministério da Saúde. HumanizaSUS: Formação de Apoiadores para a Política Nacional de Humanização da Gestão e da Atenção à Saúde, Leitura Complementar.Rio de Janeiro: Fiocruz.

AGUIAR, Katia Faria de; ROCHA, Marisa Lopes da. (2007) Micropolítica e o exercício da pesquisa-intervenção: referenciais e dispositivos em análise. Psicologia: ciência e profissão, Brasilia, v. 27, $\mathrm{n}^{\circ} 4$, p. 648-663. 
BARBOZA, T.; FRACOLLI, L. A. (2005)

A utilização do "fluxograma analisador" para a organização da assistência à saúde no Programa Saúde da Familia. Cad. Saúde Pública, Rio de Janeiro, 21(4): 10361044, jul-ago.

BRASIL. Ministério da Saúde. (2009) Acolhimento nas práticas de produção de saúde. Série B. Textos Básicos de Saúde. Brasilia: Ministério da Saúde.

BRASIL. Ministério da Saúde. Secretaria de Atenção à Saúde. (2010) Política Nacional de Humanização. Formação e intervenção. Brasîlia: Ministério da Saúde.

BRASIL. Ministério da Saúde. (2004) Cartilha da PNH: acolhimento com classificação de risco. Brasilia: Ministério da Saúde.

BUENO, Wanderlei S.; MEHRY, Emerson E. (1997) Os equívocos da NOB 96: uma proposta em sintonia com os projetos neoliberalizantes? Campinas. Disponível em: http://www.datasus.gov.br/cns/temas /NOB96/NOB96crit.htm Acesso em: 15 out. 2009.

CAMPOS, Gastão Wagner de S. (2005) Saúde Paidéia. 2 ed. São Paulo: Hucitec.

CAMPOS, Gastão Wagner de S. (1997) Considerações sobre a arte e a ciência da mudança: revolução das coisas e reforma das pessoas. O caso da saúde. In: CECILIO, Luis C. O. (org) Inventando a mudança na saúde. 2 ed. São Paulo: Hucitec.

CARNEIRO, Cleide; RUIZ, Erasmo; LANDIM, Lucyla; SAMPAIO, José Jackson. (2006) Acolher Cidadão: estratégia de aperfeiçoamento do SUS em Quixandá, Ceará. Fortaleza: Laboratório de Humanização da Saúde, Ed. UECE.

CARVALHO, Sergio R.; CAMPOS, Gastão Wagner de S. (2000) Modelos de atenção à saúde: a organização de Equipes de
Referência na rede básica da Secretaria Municipal de Saúde de Betim, Minas Gerais. Cadernos de Saúde Pública, Rio de Janeiro, v.16, n.2, p.507-515.

DEJOURS, Christophe. (2005) A Banalização da Injustiça Social. Rio de Janeiro: Editora Fundação Getúlio Vargas.

; MOLINIER, P.

(2004) O trabalho como enigma. In: LANCMAN, S.; SZNELWAR, L.I. Christophe Dejours - Da

Psicopatologia à Psicodinâmica do Trabalho. Rio de Janeiro: Ed.

Fiocruz, Brasilia: Paralelo, p.127139.

KASTRUP, Virgnia; BARROS, Regina Benevides. (2009) Movimentos funções do dispositivo na prática da cartografia. In: PASSOS, Eduardo; KASTRUP, Virginia; ESCÓSSIA, Liliana da. Pistas do método cartográfico: pesquisa-intervenção e produção de subjetividade. Porto Alegre: Sulina, p. 76-91.

LANCMAN, Selma; PEREIRA, Lygia M. de França. (2008) Introdução. In: LANCMAN, Selma (org). Politicas públicas e processos de trabalho em saúde mental. Brasîlia: Paralelo 15.

PASCHE, Dário. (2006) Política de Humanização: Apostas em Novos Modos de Fazer na Gestão e no Cuidado em Saúde. In: BRASIL. Ministério da Saúde. HumanizaSUS: Formação de Apoiadores para a Política Nacional de Humanização da Gestão e da Atenção à Saúde, Leitura Complementar. Rio de Janeiro: Fiocruz.

PASSOS, Eduardo; KASTRUP, Virgínia; ESCÓSSIA, Liliana da. (2009) Pistas do método da cartografia: pesquisa-intervenção e produção de subjetividade. Porto Alegre: Sulina.

PASSOS, Eduardo; BARROS, Regina Benevides. (2009) Por uma política da narratividade. In: PASSOS, Eduardo; KASTRUP, Virgínia; 
ESCÓSSIA, Liliana da. Pistas do método da cartografia: pesquisaintervenção e produção de subjetividade. Porto Alegre: Sulina.

PITTA, Ana Maria F. (1996) A equação humana no cuidado à doença: o doente, seus cuidados e as organizações de saúde. Saúde e

Sociedade, v.5, n.2, p. 35-60.

RAMOS, Donatela D. (2001) Acesso e acolhimento aos usuários em uma unidade de saúde de Porto Alegre/RS no contexto da municipalização da saúde. Dissertação de mestrado da Escola de Enfermagem, Universidade Federal do Rio Grande do Sul, Porto Alegre.

ROCHA, Marisa Lopes da; AGUIAR, Katia. (2003) Pesquisa-intervenção e a produção de novas análises.

Psicologia, Ciência e Profissão. Vol.23, no.4, p.64-73

ROLLO, Adail de Almeida. (2009) É possível valorizar o trabalho na saúde num mundo "globalizado"? In: SANTOS-FILHO, Serafim B.; BARROS, Maria Elizabeth Barros de. (orgs) Trabalhador da saúde: Muito prazer! Protagonismo dos Trabalhadores na Gestão do Trabalho em Saúde. Ijuí: Ed. Unijuí.

Data de submissão: 11/08/2017

Data de aceite: 30/08/2017 